\title{
REPENSANDO IDENTIDADES NA CULTURA VISUAL E NO ENSINO DAS ARTES VISUAIS
}

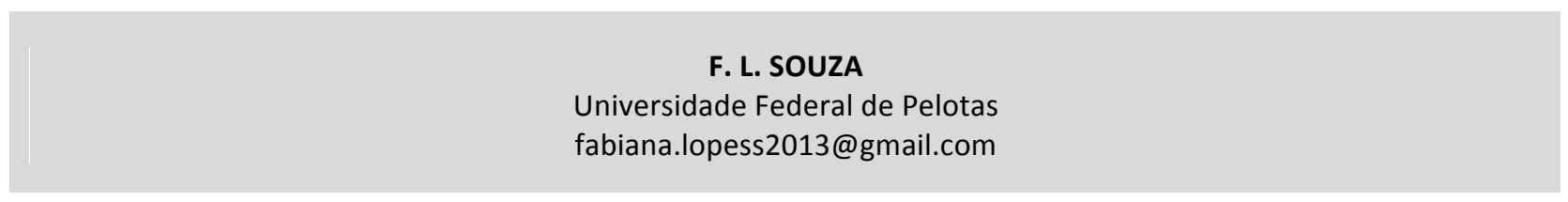

Submetido 25/06/2017 - Aceito 27/11/2018

DOI: $10.15628 /$ holos.2018.4759

\section{RESUMO}

Este texto parte de um recorte da pesquisa que foi desenvolvida junto ao Programa de Pós-Graduação em Artes Visuais/Mestrado - UFPel, na qual se objetivou investigar as percepções, os sentidos e a construção de identidades de alunos do quinto ano do ensino fundamental em contato com as imagens da cultura visual contemporânea. Procurei ainda verificar as possibilidades de mudança na apreensão destas imagens, proporcionadas pelas atividades desenvolvidas nas aulas de Artes Visuais, por meio de uma educação crítica e estética. As referências fundamentais são: Hernández (2000; 2007), que aborda a importância do trabalho com as imagens da cultura visual na escola ; Hall (2005), que trata das questões de identidade cultural na perspectiva de um mundo pós-moderno e Meira e Pillotto (2010) que refletem sobre o afeto como fator essencial nos processos de ensino e aprendizagem. Os dados foram coletados através de registros fotográficos, das imagens produzidas pelos alunos e dos relatos escritos pelos mesmos. Com os dados levantados, realizou-se análises e interpretações procurando perceber ideias centrais e/ou núcleos de sentido que emergiram com a investigação, conforme propõe Minayo (1992). Fundamentados com base no referencial proposto, os dados da pesquisa revelaram que é possível realizar um trabalho utilizando imagens e objetos do cotidiano dos estudantes, promovendo uma educação crítica e estética dos alunos a partir destas visualidades. Ainda, é relevante salientar que os estudantes demonstraram processos de identificação, pertencimento e afetos e memórias em relação às imagens escolhidas por eles para o trabalho realizado em sala de aula.

PALAVRAS-CHAVE: Cultura visual, Ensino de Artes Visuais, identidade, afeto

\section{RETHINKING IDENTITIES IN VISUAL CULTURE AND EDUCATION OF VISUAL ARTS}

\begin{abstract}
This text is part of a research that was developed by the Graduate Program in Visual Arts / Master - UFPel, in which it aimed to investigate the perceptions, the senses and the construction of student identities of the fifth year of elementary school in contact with images of contemporary visual culture. I looked also check the possibilities of change in the apprehension of these images, provided by the activities developed in Visual Arts classes, through a critical education and aesthetics. The main references are: Hernandez (2000; 2007), which addresses the importance of working with images of visual culture at school; Hall (2005), which deals with issues of cultural identity in the context of a post-modern
\end{abstract}

world and Meira and Pillotto (2010) reflecting on affection as an essential factor in teaching and learning processes. Data were collected through photographic records, the images produced by the students and the reports written by them. Based on the proposed framework, the survey data show that it is possible to work using images and everyday objects of students, promoting a critical and aesthetic education of students from these visualities. Still, it is important to note that the students showed identification processes, belonging and feelings and memories in relation to the images chosen by them for the work done in the classroom.

KEYWORDS: Visual culture, visual arts teaching, identity, affection 


\section{INTRODUÇÃO}

Os objetos, artefatos e produtos presentes na vida cotidiana, muitas vezes apresentados como de simples consumo, acabam nos fazendo esquecer qual pode ser o verdadeiro sentido e significado destes em nossas vidas. De acordo com Meira e Pillotto, "os estereótipos do consumismo na sociedade tanto servem aos que o negam como aos que a ele se submetem de modo pouco criativo e conformista" (2010, p.86).

A partir de minha própria experiência como consumidora de imagens e artefatos apresentados pelos meios de comunicação de massa, relato um fato importante sobre o contato e a influência das imagens na minha vida, esse aconteceu na época da minha adolescência, quando comecei a colecionar, sem questionamentos, objetos e imagens do Mickey Mouse, isso ocorreu meados dos anos 90 - fase final de meus estudos no ensino fundamental e início do ensino médio. A prática de colecionar esses objetos se estendeu por alguns anos, sendo expressivo o número de objetos colecionados, entre os quais podem-se citar: camisetas, chaveiros, canetas, canecas, o próprio personagem do Mickey de pelúcia, etc.

Relembrando esse fato, há pouco tempo, passei a me questionar sobre o porquê deste interesse na adolescência. Lembrei então do meu primeiro contato com o personagem do Mickey Mouse, na minha infância, quando ganhei do meu pai um boneco a corda desse personagem (figura 1), no início dos anos 1980. "Lembrar de algo implica estar afetivamente envolvido com a história que é rememorada, especialmente quando diz respeito às memórias de infância [...]" (FREITAG, 2008, p.38).

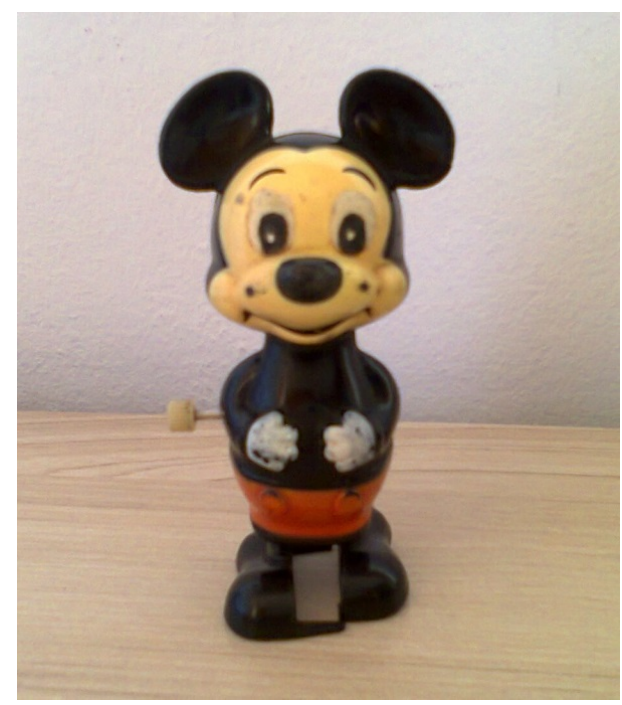

Figura 1: Objeto da pesquisadora (Mickey Mouse). Fonte: Fotografia da pesquisadora, 2014.

As coisas começaram a fazer sentido para mim, sem deixar de levar em conta o fato de que a Disney exerce grande influência ao consumo através dos inúmeros produtos com destaque nos seus personagens. 
O brinquedo que mencionei é carregado de afetos. Meu pai viajava muito e numa dessas viagens trouxe esse de presente para mim. Hoje é um dos únicos brinquedos de infância que ainda guardo comigo, ele sempre lembrava e ainda lembra meu pai.

"O afeto toca a história vital, celular e ocorre quando a emoção se repete e cria terreno permanente que dura no tempo [...] A afetividade tem origem no vínculo, contribuindo para uma conectividade significativa [...]" (CAVALCANTE 2007 apud RODRIGUES, 2009, p.47).

Sempre me questionei em relação ao quanto as pessoas eram e são influenciadas ao consumo, e também as preocupações destas em relação à imagem delas próprias, na maneira como se apresentam, baseando-se no que vivem e consomem através do contexto sociocultural. Quando falo em pessoas, não posso deixar de pensar em mim, acreditando que o interesse por uma pesquisa não aparece por acaso, isso tem a ver com o próprio pesquisador, com suas indagações, com suas ansiedades, ou com aquilo que lhe causa afeição.

Em abril de 2013, assumi como professora efetiva de Artes Visuais em uma escola municipal de um bairro de periferia da cidade de Pelotas - RS, na qual ministrei aulas para crianças da pré-escola ao 5o ano do Ensino Fundamental.

Notei que, ao trabalhar com diferentes tipos de imagens, tanto as obras consagradas da História da Arte, ou mesmo aquelas provenientes de revistas e/ou outros materiais, houve um grande interesse por parte dos alunos em conversar sobre essas imagens, falando sobre o que achavam destas e até mesmo se já eram conhecidas de algum lugar.

Assim, resolvi elaborar um projeto de pesquisa para o programa de Pós-Graduação em Artes Visuais - Mestrado ${ }^{1}$, com o objetivo de investigar as percepções e sentidos vivenciados pelos estudantes no seu cotidiano quanto à construção de suas identidades, em contato com as imagens da cultura visual; e ainda, quais as possibilidades de mudança na apreensão destas, proporcionadas pelas atividades desenvolvidas nas aulas de Artes Visuais, por meio de uma educação crítica e estética.

O presente texto é um recorte da pesquisa, no qual destaco categorias, as quais serão abordadas nos capítulos seguintes.

\section{IDENTIDADE, AFETO E CULTURA VISUAL}

O indivíduo constrói sua identidade através de informações, experiências e das interrelações com os outros. De acordo com Medeiros, [...] identidade significa um conjunto de critérios de definição de um indivíduo

e um sentimento interno composto de diferentes sensações, tais como sentimento de unidade, de coerência, de pertencimento, de valor, de autonomia e de confiança. Esses diferentes ingredientes afetivos e cognitivos representam os processos internos através dos quais o psiquismo organiza todas as informações que ele recebe em um todo coerente (2008, p.34).

\footnotetext{
${ }^{1}$ Sob orientação da profa. Dra Ursula Rosa da Silva. Pesquisa financiada pela Coordenação de Aperfeiçoamento de Pessoal de Nível Superior (CAPES).
} 
O processo de identidade se dá através das vivências de cada pessoa em seu meio social: família, escola, amigos, entre outros grupos. Segundo Medeiros as marcas de semelhanças

colhidas nas categorias e grupos de pertencimento vêm a ser condição indispensável à construção da identidade individual. O comportamento individual não pode ser, portanto, entendido sem que seja levado em conta o comportamento coletivo (2008, p.43).

A construção da identidade é diretamente relacionada com a vida em sociedade envolvendo crenças, valores e representações em um processo de identificação com um grupo.

De acordo com Oliveira, "[...] trazemos em nossa constituição identitária marcas que não são todas suaves, amenas, alegres, belas, idealizadas. Trazemos também nossas dores, nossas feiúras. É necessário pensar também sobre o quanto a escola esquece de assumir seus reais alunos"(2018, p.174).

A escola é um dos lugares em que determinados grupos se constituem a partir de afinidades e processos de identificação e pertencimento, como também é o lugar que reforça diferenças e desigualdades.

Para Hernández, indivíduos que nascem em uma mesma cultura, aprendem e constroem comportamentos e atitudes afins. "A identidade é dada culturalmente e se apresenta como naturalizada e estável, oferecendo elementos de discriminação em relação a grupos com afinidades de gênero, etnia, religião ou pátria" (2007, p.72).

O excesso de informações e o consumo de produtos é um dos fatores que age diretamente nas possíveis mudanças que ocorrem na construção de identidade de uma pessoa, e esta se dá através de um processo de formação contínua, ao longo do tempo e das experiências adquiridas.

Kaminski (2010) afirma que os valores conceituais dos produtos adquiridos são transferidos para quem os consome e, consequentemente, julgados pelos demais integrantes sociais, diferenciando assim um sujeito do outro e criando uma identidade cultural e uma individualidade mascarada. Levando em consideração o processo apontado pela autora, ocorre a inclusão e exclusão dos indivíduos em determinados grupos sociais, baseada em referências escolhidas para a diferenciação entre as pessoas.

\subsection{Educação pelo afeto}

A partir da necessidade de inserção e pertencimento das pessoas em determinados grupos sociais e a exposição ao cotidiano carregado de informações, é relevante destacar a importância de pensarmos em uma educação que tenha por base o afeto ${ }^{2}$, que produza sentidos. De acordo com Meira e Pillotto, a escola,

apesar das inúmeras pesquisas realizadas sobre métodos contemporâneos para a educação, ainda continua priorizando em suas práticas um ensino e uma aprendizagem voltados ao pensamento linear, disciplinar, técnico e, consequentemente, dando importância maior aos aspectos cognitivos que aos afetivos. Para a maioria das escolas, o

\footnotetext{
${ }^{2}$ O termo afeto é definido como qualquer espécie de sentimento e emoção relacionada a ideias ou a complexos de ideias; enquanto que a afetividade significa, não apenas os afetos, mas sobre tudo, os sentimentos de agrado e desagrado (CABRAL; NICK, 1999 apud MEIRA; PILLOTTO, 2010, p.13).
} 
saber intelectual é que vai garantir sucesso no mercado de trabalho. Nesta perspectiva, vale apontar que ensinar e aprender pela via da razão separada do afeto e do sensível não satisfaz as condições necessárias a uma formação integral (2010, p.24).

As práticas escolares de ensino e aprendizagem ainda estão muito centradas em um conhecimento condicionado e linear, preocupando-se mais em formar profissionais e esquecendo a importância de se articular os conteúdos ao contexto dos estudantes, aquilo que de alguma maneira faz sentido para eles e produz afeto.

Afeto e conhecimento não devem ser pensados separadamente um do outro. "Educar pelo afeto pode ser um caminho possível, um caminho de maravilhamento capaz de modelar e modular paixões alegres que motivem atos de conhecimento e compreensão compatíveis com os desafios do presente" (MEIRA; PILLOTTO, 2010, p.38). O conhecimento como algo a ser construído, se for trabalhado do ponto de vista dos afetos, produzirá sentidos aos estudantes contemplando as dimensões cognitiva e intuitiva.

Nesse contexto, mais especificamente nas aulas de artes, em que teoria e prática partem de um processo criativo, um trabalho reflexivo, intuitivo e sensível, torna-se essencial compreender isso tanto por parte dos alunos quanto do professor.

É preciso que o professor perceba os gostos e interesses dos estudantes para o planejamento das aulas e tenha um olhar crítico e reflexivo frente a seus próprios interesses para não vir somente a reproduzir aquilo que absorveu da cultura de consumo e dos meios de comunicação e informação.

\subsection{Cultura Visual}

Os estudos referentes à cultura visual nas artes vão além das visualidades artísticas, procurando investigar também as imagens produzidas pela mídia e todas as provenientes da vida cotidiana.

As representações visuais formam a cultura pós-moderna, determinando normas, formando o olhar e contribuindo na formação de valores das pessoas. Estamos expostos o tempo todo às visualidades presentes no cotidiano, em que o consumo,

\footnotetext{
o tempo acelerado, o excesso de informações a que somos submetidos diariamente passa a nos definir como integrantes de um mundo conectado, interligado, fugaz, caótico, de mudanças por vezes desconcertantes. Em nosso cotidiano, as imagens decorrentes destas mudanças desempenham um papel que, muitas vezes, nos escapa. Compreender o vitalismo destas imagens a partir de um campo amplo e complexo, como o da cultura visual, passa a ser, então, um passo de extrema importância para a educação, especialmente para a educação em arte (MEIRA; SILVA, 2013, p.40).
}

Os estudantes têm acesso a um universo de imagens e estas se propagam por diversos meios: televisão, videogames, computadores, entre outros. "Buscar exemplos na cultura que nos cerca tem a função de aprender a interpretá-los a partir de diferentes pontos de vista e favorecer a tomada de consciência dos alunos sobre si mesmos e sobre o mundo de que fazem parte" (HERNÁNDEZ, 2000, p.30). 
As percepções e sentidos atribuídos às imagens e objetos da cultura visual apresentam, na maioria das vezes, distinção entre as qualidades estéticas e o que estes estão representando realmente.

De acordo com Hernández (2000), os artefatos visuais são produtos de um contexto histórico, cultural e social que podem afetar a percepção e a estética.

Para a compreensão da cultura visual é necessário estar atento aos diferentes tipos de representações visuais de diferentes culturas. Objetos consagrados da história da arte do passado fazem parte da cultura visual, assim como os produzidos no presente e também as diferentes manifestações visuais.

Segundo Barreto, [...] na atualidade, o papel do/a professor/a na aprendizagem, talvez seja, justamente, encontrar e dispor percursos diversos e alternativos que contemplem as diferentes formas de ver que constituem as diferenças individuais em uma turma e, em uma mesma faixa etária, em crianças que fazem parte de contextos sociais distintos e que partilham também de diferentes culturas (2018, p.182).

O trabalho do professor de Artes Visuais, para uma compreensão crítica dos estudantes em contato com a cultura visual, deve contemplar as experiências dentro e fora da sala de aula. Conforme Hernández (2000), as estratégias de compreensão vêm de diferentes manifestações da cultura visual

[...] não só dos objetos considerados canônicos, mas sim dos que se produzem no presente e aqueles que fazem parte do passado; os que se vinculam à própria cultura e com as de outros povos, mas ambas desde a dimensão de "universo simbólico"; os que estão nos museus e os que aparecem nos cartazes publicitários e nos anúncios; nos videoclips ou nas telas da internet; os realizados pelos docentes e pelos próprios alunos (p.50).

As imagens e artefatos visuais a serem estudados nas aulas de Artes Visuais não devem ser limitados a critérios de gosto, mas sim a propostas de compreensão destas representações.

O estudo das visualidades das diferentes culturas e em diferentes épocas deve auxiliar os estudantes a decodificarem os símbolos e signos presentes nestas visualidades e terem uma melhor percepção sobre o mundo no qual estão inseridos. Segundo Hernández (2000), a cultura visual contribui

para que os indivíduos fixem as representações sobre si mesmos e sobre o mundo e sobre seus modos de pensar-se. A importância primordial da cultura visual é mediar o processo de como olhamos e como nos olhamos, e contribuir para a produção de mundos [...] (p.52).

As pessoas são influenciadas quanto à construção de suas identidades, e a cultura visual acaba transmitindo valores e interferindo nas subjetividades destas pessoas. Como exemplo disso, temos as imagens e objetos que são vivenciados e consumidos diariamente por crianças, jovens e adolescentes. Ao tratar de uma perspectiva educativa, Hernández (2000), aponta que

[...] os objetos da cultura visual que maior presença têm entre os meninos, as meninas e os adolescentes são os que recobrem as paredes dos quartos, as imagens das pastas da escola, as revistas que lêem, os programas de televisão a que assistem, as representações dos grupos musicais, os jogos de computador, suas imagens na Internet, a roupa, seus ícones populares, etc. (p.136). 
Uma educação baseada nas imagens da cultura visual deve levar em conta as experiências visuais dos estudantes, ajudando-os na compreensão destas visualidades sem interferir nas suas preferências e gostos por determinados objetos e/ou artefatos visuais.

De acordo com Hernández (2007), o propósito da compreensão crítica

e performativa da cultura visual é procurar não destruir o prazer que os estudantes manifestam, mas "explorá-lo para encontrar novas e diferentes formas de desfrute", oferecendo aos alunos possibilidades para outras leituras e produções de "textos", de imagens e de artefatos (p.71).

O professor de Artes Visuais será mediador e provocador no processo educativo com o estudo das imagens da cultura visual, ajudando o aluno a adquirir novos conhecimentos, podendo este atribuir novos sentidos e significados às visualidades presentes na vida cotidiana.

As imagens são importantes para promover o olhar crítico e estético dos estudantes, desde as reproduções de obras de Arte do passado até as imagens midiáticas que nos invadem com seus anúncios do que é bom, de como devemos ser, nos comportar e nos vestir. Em conformidade com Hernández, [...] é necessário recordar

que uma das maneiras mais notórias pelas quais as mídias, as representações e as práticas da cultura visual posicionam crianças e jovens é através dos "textos" da cultura popular, em particular dos que tendem a criar identidades de etnia, gênero, sexo e consumidor (2007, p.74).

Na pós-modernidade, imagens da mídia e de consumo se apresentam frequentemente, influenciando-nos muitas vezes sem que possamos perceber. Nossas identidades vão se construindo e se modificando através das relações que estabelecemos com este universo visual e também da inter-relação com as outras pessoas.

$\mathrm{O}$ acesso às mais variadas imagens se dão pelos meios de tecnologia de informação e comunicação. É possível perceber na contemporaneidade crianças, adolescentes, jovens e adultos conectados o tempo todo à internet com seus celulares, tablets, computadores e notebooks, isso sem falar nos programas de TV, jogos de computadores entre outros.

Para Hernández (2007, p.25), "[e]m um mundo dominado por dispositivos visuais e tecnologias da representação (as artes visuais como tais), nossa finalidade educativa deveria ser a de facilitar experiências críticas reflexivas". Além do estudo das imagens da cultura visual contemporânea nas aulas de Artes Visuais, os estudantes poderão compreender o quanto estas imagens podem influenciá-los sobre seus comportamentos e na construção de suas identidades.

Nesse processo de educação considerando a cultura visual, o professor de Artes deve observar as experiências que os estudantes trazem para a sala de aula, pois como aponta Hernández (2000),

[os] alunos são o resultado de contextos socioculturais concretos e de épocas históricas que representam um determinado tipo de valores. Eles têm acesso à escola com uma identidade, uma biografia em construção, baseada em suas experiências de gênero, etnia e classe social e com uma série de noções sobre a autoridade e o saber. Trazem consigo não apenas conhecimentos, mas construções da sociedade e de si mesmos, baseadas em suas experiências socioculturais anteriores (p.141). 
Quando os estudantes entram para a escola carregam junto seus conhecimentos fora dali, tudo aquilo que foi adquirido em seus contextos socioculturais, o que é vivido em seus cotidianos e o que já foi construído em com base nestes conhecimentos.

\section{FALANDO DA PESQUISA}

Como encaminhamento de pesquisa, elaborei um projeto de ensino cuja proposta foi a elaboração de desenhos de si mesmos feitos por alunos de duas turmas de 5ㅇano. 0 objetivo do projeto de ensino foi promover um olhar estético a partir do contato com imagens da cultura visual, (retratos, autorretratos, fotografias), desenvolvendo a percepção e a criticidade em relação a estas imagens.

A metodologia do projeto de ensino consistiu em contextualizar e apresentar imagens de autorretrato de alguns artistas de diferentes períodos históricos, e propor uma atividade de desenho de autorretrato com a intervenção de imagens de revistas e outros materiais. Para isso, os alunos deveriam utilizar técnicas de recorte, colagem como também pintura dos desenhos com lápis de cor.

Ampliando as fontes de buscas de imagens, visto que os alunos haviam somente recolhido imagens de revistas e encartes publicitários, que eram materiais disponíveis no momento, solicitei ainda que eles escolhessem objetos ou imagens presentes em seu cotidiano e levassem para as aulas de Artes Visuais.

Este trabalho teve uma abordagem qualitativa, do tipo estudo de caso, no qual imagens e textos produzidos pelos alunos foram analisados e fundamentados com base nos referenciais teóricos.

Para Stake (1994 apud ANDRÉ, 2005, p.16), o "estudo de caso não é uma escolha metodológica, mas uma escolha do objeto a ser estudado". As técnicas de coleta de estudos de caso são: observações, entrevistas, análise de documentos, anotações de campo e gravações.

Na figura 2, apresento o trabalho da primeira atividade de autorretrato da aluna Daiane ${ }^{3}$ que selecionou várias imagens de objetos e produtos de consumo para compor seu trabalho. Quando ela foi solicitada a levar para a aula objetos de seu cotidiano, selecionou algumas fotos de sua família, demonstrando que seus interesses, seus afetos e suas percepções não se limitam apenas às ofertas das visualidades contemporâneas (figura 3 ).

\footnotetext{
${ }^{3}$ Neste texto os alunos são identificados por nomes fictícios.
} 


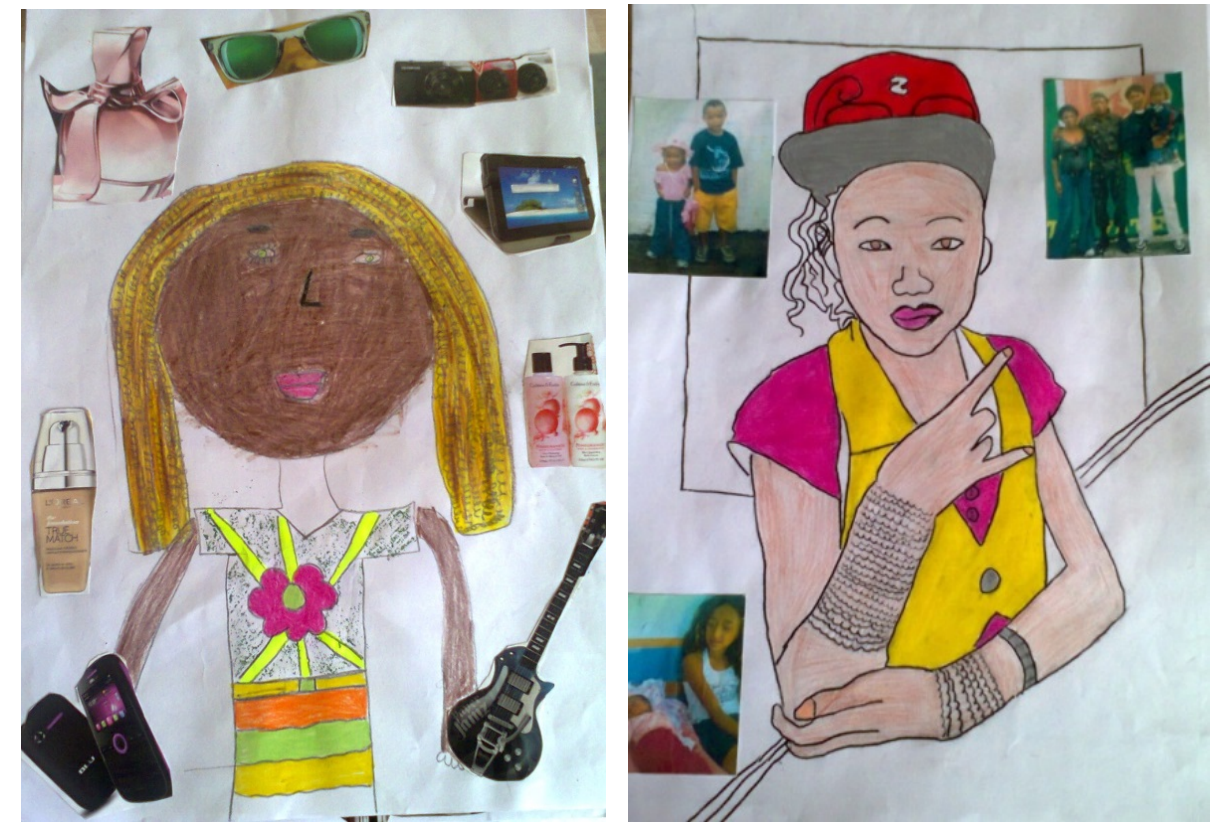

Figuras 2 e 3: À esquerda, autorretrato e interferências; à direita, autorretrato e objetos, (Daiane). Fonte: Fotografia da pesquisadora, 2014.

Em um breve relato sobre sua escolha pelas fotos, Daiane descreve: "Para mim a família é muito importante, amorosa e divertida, amo minha família, meus amigos, são as pessoas mais importantes".

$\mathrm{Na}$ escolha por objetos seus, em sua casa, a aluna selecionou três fotografias, nas quais ela está com familiares e no relato ela destaca a importância da família em sua vida. Segundo Nery et al. (2015, p.48), "tanto os objetos quanto as fotografias, [...] quando ligados à história da família e ao vínculo e memória familiar, são ainda mais importantes e marcantes".

As fotografias traziam lembranças à aluna e demonstravam a relação de afetividade que ela tinha com seus familiares, algo importante que fazia parte de sua memória e queria que compusesse seu desenho de autorretrato.

O mesmo fato aconteceu nas escolhas do aluno Júnior que selecionou para a atividade (figura 4) fotos de seus animais de estimação (figuras 5 e 6 ). 


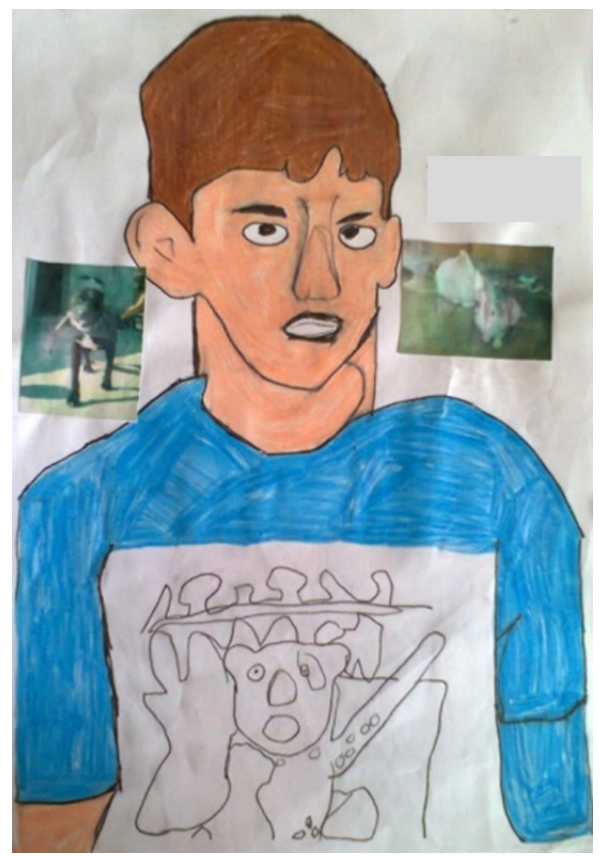

Figura 21: Autorretrato e objetos (Júnior).

Fonte: Fotografia da pesquisadora, 2014.
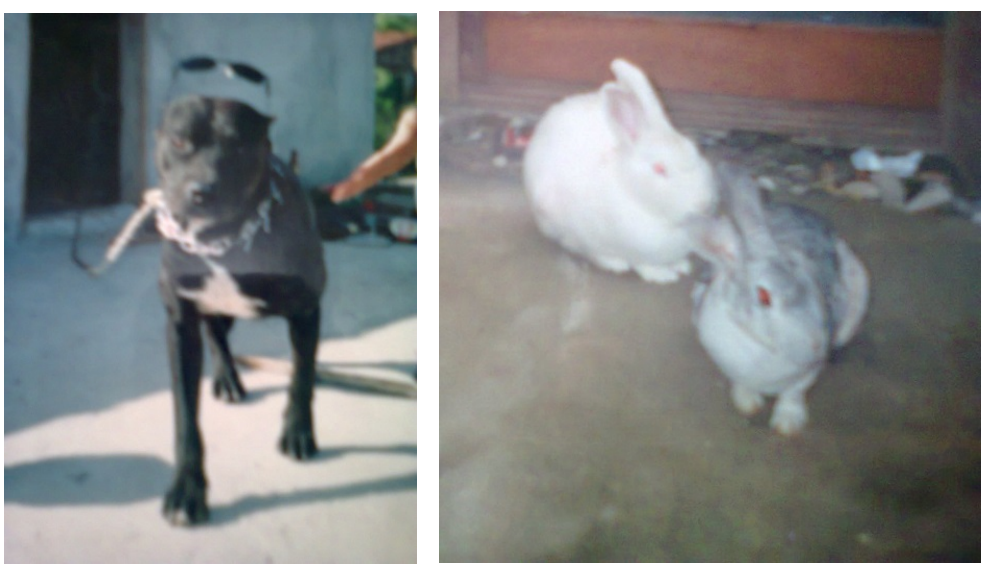

Figuras 22 e 23: Fotografias do aluno Júnior. Fonte: Fotografia da pesquisadora, 2014.

Ao ser questionado sobre as lembranças que traziam as fotos dos animais de estimação escolhidas por ele, Júnior respondeu-me: "Felicidade". Em outra pergunta feita a Júnior, sobre de quem ele havia ganhado os animais, ele disse-me: "Do meu pai". E ainda questionei: o que esta pessoa significa para você? E o aluno respondeu: "É o melhor pai do mundo".

Os autorretratos realizados pelos alunos Daiane e Júnior chamaram minha atenção para o fato de que é possível realizar um projeto que desenvolva as percepções e os sentidos dos estudantes, trabalhando com objetos e imagens de seus cotidianos, de seus contextos e ainda contribuindo para uma educação estética.

A experiência estética acontece quando há uma relação estabelecida entre a pessoa e o objeto, e os sentidos e significados dependem do processo subjetivo de cada pessoa. Da mesma forma, a compreensão crítica em relação às imagens presentes na cultura visual do aluno pode 
contribuir para que este e seu professor discutam sobre aquilo que é vivido cotidianamente, auxiliando-os em suas memórias, percepções, sentidos e afetividades.

Para Meira (2009), os objetos e as imagens a serem contempladas no cotidiano e que nos levam a possibilidades de obtermos uma experiência estética, são na maioria das vezes elementos efêmeros, mas capazes de nos tocar através da maneira como estabelecemos relações com os mesmos.

Neste caso estudado, as fotos selecionadas pelos alunos em suas casas, poderiam passar despercebidas, se não fossem solicitados a serem trazidas para o ambiente de sala de aula.

Quando os alunos estão em contato com a variedade de imagens proporcionadas pelos meios de comunicação e informação, seja pelo computador, televisão, propagandas, revistas, entre outras, suas escolhas são muitas vezes influenciadas e direcionadas ao consumo por objetos e imagens que gostariam de possuir e até mesmo se identificar visualmente. De acordo com Meira e Pilotto, a maneira como nos mostramos,

\footnotetext{
é indissociável da forma pelas quais as coisas e os outros se apresentam para nós. A ação prática permite tecer microidentidades como parte de um micromundo. A expressão "conhecimento corporificado" depende das experiências que advêm do fato de ter um corpo, de ele ser dotado de diversas capacidades envolvidas no contexto biológico e cultural mais abrangente $(2010$, p.15).
}

Nesta pesquisa, quando os alunos foram solicitados a levar para as aulas de Artes Visuais imagens ou objetos particulares de suas casas, estes demonstraram que não estão limitados a sentimentos de afeição somente pelas imagens da cultura visual contemporânea, nem por aquelas que os direcionam prioritariamente ao consumo. É possível pensar sobre isso, quando das suas escolhas e relatos sobre a importância da família e desse tipo de afetividade em suas vidas.

Outro fato importante acontecido durante a atividade foi a motivação dos alunos ao construírem seus desenhos de autorretratos, com suas fotos. Eles ficaram muito felizes com o resultado de seus trabalhos e a proposta dada pela professora. Para Meira e Pilloto, tão importante quanto o afeto

é a forma de motivação apropriada pelos professores no contexto educacional, pois a motivação é também movida pela afetividade, cujas relações são construídas pelos interesses, pelos desafios, pelos impulsos, pelas emoções e por todos os sentimentos que são capazes de afetar/ tocar uma pessoa (2010, p.20).

Além da dedicação demonstrada pelos alunos ao levarem seus objetos e imagens para as aulas, eles demonstraram afeto e um real interesse pela atividade. Muitos deles queriam posar para fotos, outros queriam as fotos do perfil do Facebook, perguntando o que eu achava das fotos que eles escolhiam para formar o desenho. Houve bastante interação durante as aulas, todos conversavam e queriam saber sobre os objetos e imagens dos colegas.

O compartilhamento de informações resultante da dinâmica das interações ocorridas em sala de aula propiciou um ambiente em que todos aprenderam juntos. Assim, "um ser humano aprende [...], na interação e no contato com o outro, com suas paixões e criatividades liberadas vai acessar a curiosidade, a inventividade e a criação" (RODRIGUES, 2009, p.46).

Além do processo criativo e construtivo por parte dos alunos, a atividade com os autorretratos provocou curiosidade e interação entre os mesmos. 
O trabalho da figura 30, realizado pela aluna Laura, à principio, demonstra uma diferença na escolha pelos objetos, se comparado às seleções dos outros alunos que preferiram fotos com familiares, fotos de animais de estimação e bichos de pelúcia.

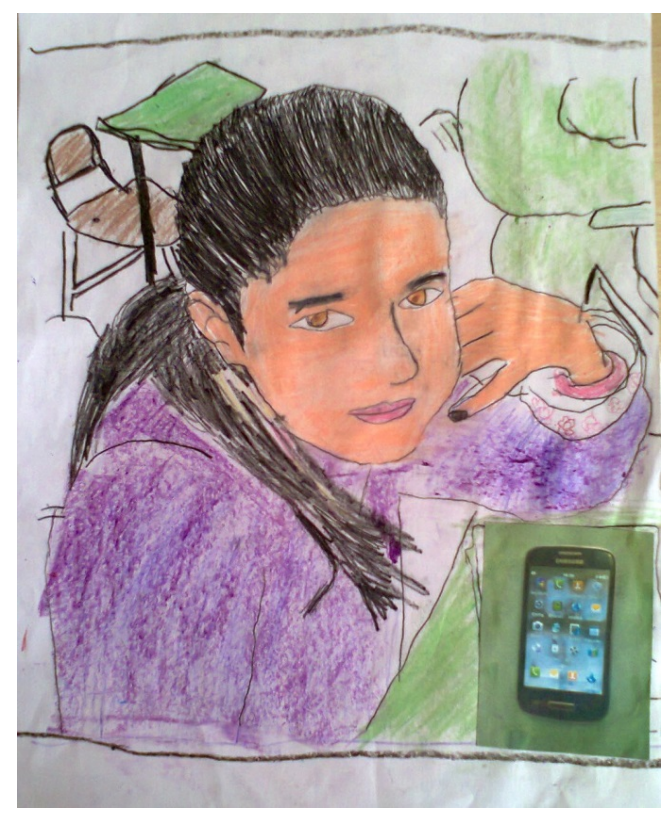

Figura 30: Autorretrato e objetos (Laura).

Fonte: Fotografia da pesquisadora, 2014.

Laura levou seu celular como objeto a compor o autorretrato e justificou sua escolha dizendo: "[...] eu gosto muito dele, [e o que o celular me lembra] tá na galeria de fotos". Perguntei de quem ela havia ganhado, e o que essa pessoa representava para ela; ela respondeu-me: "da minha vó, é como uma mãe".

Em resposta à minha pergunta, a aluna fala sobre a galeria de fotos do celular, ou seja, o celular é o objeto a constituir seu autorretrato, pois representa seus momentos importantes, afetos que ficaram registrados na memória do celular e que podem ser lembrados a qualquer momento, como em um álbum de fotografias. Segundo Freitag (2008, p.39), “[...] a memória é algo vivo e móvel, está constantemente presente na constituição social do sujeito e na forma como se analisam e se resignificam as histórias".

O celular poderia ser analisado como um simples objeto de consumo, mas representava mais do que isso, pois era algo que continha recordações carregadas de sentidos para a aluna. Além disso, ela afirmou ser um presente da avó, pela qual ela se referiu com um sentimento de amorosidade quando a comparou com a mãe. Os sentimentos nos traduzem, "revelam [...] quem somos nós a nos relacionarmos com com os outros, o retrato de nossas mutações imediatas orquestradas por emoções, modificações químicas e neurais, mas sobretudo, interacionais, conectivas" (MEIRA; PILLOTTO, 2010, p.125).

As fotografias salvas no celular serviam para a aluna recordar e reviver experiências e acontecimentos que foram vivenciados por ela.

Pedi ainda à aluna para que escrevesse brevemente sobre a sua escolha. Ela me entregou um pequeno texto com o título "O primeiro celular" que dizia o seguinte: 
Era uma vez uma menina que queria um celular e sua mãe não tinha dinheiro e condições de comprar. E um dia sua mãe deu um para sua filha, mas não era o que ela queria, e a menina começou a trabalhar e começou a juntar dinheiro e falou para a sua mãe, vou comprar um celular que ela queria. Fim (RELATO DA ALUNA, 2014).

O relato escrito por Laura parecia mais com uma história criada por ela mesma, pois começava dizendo "Era uma vez [...]" e se referia a uma menina sem afirmar ser ela. Na verdade, a história escrita pela aluna faz parte de sua realidade como também da realidade de várias meninas e meninos daquele contexto escolar em que, em sua maioria, as famílias possuem nível sócioeconômico baixo.

Além do relato, o desenho dela também chamou minha atenção, quanto à representação. Ela desenhou sua imagem a partir de uma foto que tiramos em sala de aula, mas teve a preocupação de desenhar um fundo, em que apareciam as mesas e cadeiras da sala.

Laura passava o dia inteiro na escola, pois participava do Projeto Mais Educação ${ }^{4}$. A escola, na maioria das vezes, é o lugar mais importante na vida dos alunos, pois estes vivem em condições precárias e enfrentam uma série de problemas fora da escola. Será que a representação dos objetos característicos da sala de aula no desenho não queria demonstrar o quanto a escola é significativa na vida da aluna e de outros tantos estudantes?

Pelo relato e pelo desenho de Laura, é possível pensar sobre a importância de uma educação que leve em conta os processos afetivos dos estudantes. Cruz (2009) afirma que independente de onde provém,

\begin{abstract}
o afeto é a confluência da educação essencial. Seja na sala de aula [...] pelas paredes que separam as categorias de alunos $a, b$, e c que equivocadamente os profissionais tendem a categorizar para supostamente melhor trabalhar as dificuldades, sem darem-se conta de que as salientam alimentando estigmas. Seja nos muros altos que na tentativa vã de trabalhar para incluir, cada vez mais excluem e distanciam do meio social maior portadores de deficiência. Das casas frias, compostas por pessoas com mãos escorregadias que não têm tempo para o afago, nem ouvidos para a escuta, nem do olhar mais profundo dos pais para os filhos[...], que buscam em seus investimentos profissionais, melhor prover as famílias, sem divisar as reais necessidades a serem supridas. E assim, a vida segue seu rumo num rio que nunca trará as mesmas águas, onde o tempo passa e os afetos se perdem, onde a sensibilidade não tem fluxo (p.74-75).
\end{abstract}

Um trabalho em sala de aula que envolva sensibilidade e afetividade dará condições ao professor de perceber as reais necessidades dos alunos. A troca de experiências e a mediação de conhecimentos, de maneira reflexiva, possibilitam uma melhor relação entre ambos, auxiliando ainda na desconstrução de estigmas e condicionamentos.

\title{
4 CONSIDERAÇÕES FINAIS
}

\footnotetext{
${ }^{4}$ Criado pela Portaria Interministerial no $17 / 2007$ e regulamentado pelo Decreto 7.083/10, constitui-se como estratégia do Ministério da Educação para indução da construção da agenda de educação integral nas redes estaduais e municipais de ensino que amplia a jornada escolar nas escolas públicas, para no mínimo 7 horas diárias, por meio de atividades optativas nos macrocampos: acompanhamento pedagógico; educação ambiental; esporte e lazer; direitos humanos em educação; cultura e artes; cultura digital; promoção da saúde; comunicação e uso de mídias; investigação no campo das ciências da natureza e educação econômica (PROGRAMA MAIS EDUCAÇÃO, 2015).
} 
Nas atividades de autorretratos, foi promovida a experiência estética, desde a apreciação e leitura de imagens de artistas aos estudantes, como também na construção de autorretratos por meio de escolhas pessoais, tanto por imagens publicitárias, quanto as de seus próprios cotidianos.

Houve interação e diálogo nas aulas, além de relatos escritos sobre suas escolhas, abriu-se um espaço em sala de aula para exposição de suas experiências, histórias afetos e memórias. Dessa forma, ocorreu uma reconstrução de experiências significativas, por meio da reflexão de alguns momentos vivenciados em seus cotidianos.

As percepções e sentidos dos estudantes foram aguçados durante estas atividades, em que o trabalho com objetos pertencentes aos alunos ocasionou envolvimento, dedicação e a valorização daquilo que foi significativo para eles.

Observei que foi desenvolvida uma visão crítica nas atividades de Artes Visuais, na medida em que propus uma metodologia para o desenvolvimento do processo de descondicionamento dos alunos pela escolha de imagens publicitárias prioritariamente, pois, ao invés destas, os estudantes passaram a levar objetos e imagens de suas casas, pertencentes a eles e/ou familiares.

No trabalho com os objetos houve mais diálogo e a demonstração por parte dos estudantes, a princípio, de um olhar crítico, quando relataram a importância dos momentos com a família, dos arquivos de fotos do celular, do significado dos ursinhos de pelúcia, entre outros.

Por fim, percebo que a presente pesquisa torna-se relevante para a contribuição dos estudos referentes às imagens da cultura visual, do ensino das Artes Visuais e da construção identitária dos educandos, considerando as visualidades presentes em suas vidas e entendendo a importância de uma educação baseada no afeto e na expressão das memórias individuais e coletivas.

\section{REFERÊNCIAS}

ANDRÉ, Marli Eliza Dalmazo Afonso de. (2005). Estudo de caso em Pesquisa e Avaliação Educacional. Brasília: Liber Livro.

BARRETO, Umbelina. Conversa a roda da visualidade na contemporaneidade. QUEIROZ, João Paulo \& OLIVEIRA, Ronaldo (2018, Org.). Os riscos da Arte: Educação, Mediação e Formação. Lisboa: Universidade de Lisboa, Faculdade de Belas-Artes, Centro de Investigação e Estudos em BelasArtes (CIEBA), 177-186. Recuperado em 26 de nov. 2018 de: http://congressomateria.fba.ul.pt/rede/2018_rede_02_17_Umbelina.pdf

CRUZ, Patrícia. (2009, Org.). Sentindo sentidos: uma incursão aos afetos, o paraíso esquecido. In: CENTRARTE. Arte-terapia e educação: a arte de tecer afetos e cuidados. Porto Alegre: Laçus, 73-87.

FREITAG, Vanessa. (2008). Tecendo os fios das memórias de infância no processo criativo docente: Um estudo com professoras de Artes Visuais da casa de Cultura de Santa Maria/RS. $175 f$. Dissertação (Mestrado - PPGE/UFSM) Universidade Federal de Santa Maria, Santa Maria. Recuperado em: 26 de nov. 2018, de: http://cascavel.ufsm.br/tede/tde_busca/arquivo.php?codArquivo=1873

HERNÁNDEZ, Fernando. (2000). Cultura Visual - Mudança Educativa e projeto de trabalho. Porto 
Alegre: Artmed.

HERNÁNDEZ, Fernando. (2007). Catadores da Cultura Visual - proposta para uma nova narrativa educacional. Porto Alegre: Mediação.

KAMINSKI, Evelyse. (2010, Janeiro/Abril). Consumo: uma construção identitária cultural na sociedade contemporânea. Revista de Estudos da Comunicação, Curitiba, v. 11, n. 24, 31-38, $\begin{array}{lllll}\text { Recuperado em } & 26 & \text { nov. 2018, de }\end{array}$ :http://www2.pucpr.br/reol/pb/index.php/comunicacao?dd1=3860\&dd99=view\&dd98=pb

MEC. Programa mais educação. Recuperado em 26 de nov. 2018 de: http://portal.mec.gov.br/programa-mais-educacao/apresentacao?id=16689

MEDEIROS, João Luiz. ELEMENTOS DE ANÁLISE PARA A CONSTRUÇÃO DE IDENTIDADES. In: MEDEIROS, João Luiz. (2008, Org.) Identidades em Movimento: Nação, Cyberespaço, Ambientalismo e Religião no Brasil Contemporâneo. Porto Alegre: Sulina, 27-62.

MEIRA, Marly Ribeiro. Educação estética, arte e cultura do cotidiano. In: PILLAR, Analice Dutra. (2009, Org.). A Educação do Olhar no ensino das artes. 5a ed. Porto Alegre: Mediação, 121140.

MEIRA, Marly Ribeiro; PILLOTTO, Silvia Sell Duarte. (2010). Arte, afeto e educação: a sensibilidade na ação pedagógica. Porto Alegre: Mediação.

MEIRA, Mirela R; SILVA, Ursula Rosa da. (2013). Cultura visual, Ensino da Arte e Cotidiano: Hibridismos e Paradoxos. Revista Visualidades. Goiânia, v 11, n² 2, 37-57. Recuperado em: 26 de nov. 2018 de: http: //www.revistas.ufg.br/VISUAL/article/viewFile/30684/16684

MINAYO, Maria Cecília de Souza. (1992). O Desafio do Conhecimento: pesquisa qualitativa em saúde. São Paulo: Editora Hucitec/Rio de Janeiro: Abrasco.

NERY, Olivia S; HUZSAR, Frantieska S; FERREIRA, Maria Letícia M; MICHELON, Francisca F.(2015, Janeiro/Abril). Caixas de memórias: a relação entre objetos, fotografias, memória e identidade ilustradas em cenas da ficção, Ciências Sociais, Unisinos, São Leopoldo, Vol. 51, N. 1, 42-51. Recuperado em: $26 \quad$ nov. 2018 de: revistas.unisinos.br/index.php/ciencias_sociais/article/view/csu.2015.51.1.05

14. OLIVEIRA, Ronaldo. CONSTRUÇÃO CURRICULAR E PRODUÇÃO DE SENTIDO: pela inclusão curricular das histórias de si nos processos de formação. In: QUEIROZ, João Paulo \& OLIVEIRA, Ronaldo (2008, Org.). Os riscos da Arte: Educação, Mediação e Formação. Lisboa: Universidade de Lisboa, Faculdade de Belas-Artes, Centro de Investigação e Estudos em BelasArtes (CIEBA), 167-176. Recuperado em 26 de nov. 2018 de: http://congressomateria.fba.ul.pt/rede/2018_rede_02_16_Ronaldo.pdf

RODRIGUES, Rute. (2009, Org.) Educação Afetiva: aprendendo a ser e a conviver. In: CENTRARTE. Arte-terapia e educação: a arte de tecer afetos e cuidados. Porto Alegre: Laçus, 45-87. 